\title{
AS CONCEPÇÕES DE EDUCAÇÃO AMBIENTAL DOS(AS) PROFESSORES(AS) NAS ESCOLAS MUNICIPAIS DE MATINHOS, BRASIL
}

\author{
CONCEPCIONES DE EDUCACIÓN AMBIENTAL DE MAESTROS EN LAS \\ ESCUELAS MUNICIPALES DE MATINHOS, BRASIL
}

\author{
THE TEACHER'S CONCEPTIONS OF ENVIRONMENTAL EDUCATION IN \\ MUNICIPAL SCHOOLS OF MATINHOS, BRAZIL
}

\author{
Ruth Kellen Catão CHAVES ${ }^{1}$ \\ Emerson JOUCOSKI ${ }^{2}$ \\ Christiano NOGUEIRA ${ }^{3}$
}

RESUMO: Este artigo apresenta uma análise das concepções de Educação Ambiental de professores(as) das escolas municipais de Matinhos, no estado do Paraná, Brasil. A pesquisa foi de cunho quantitativo e qualitativo. No primeiro, foi elaborado um questionário, cujas questões se basearam em temas gerais da Educação Ambiental, considerando as relações entre o ser humano e o meio ambiente, em que houve a participação de 51 professores(as). A análise ocorreu através do levantamento estatístico. No segundo, foram realizadas entrevistas com 13 professores(as) que foram transcritas e analisadas através da técnica da Análise Textual Discursiva. Os resultados mostram aspectos preservacionistas/conservacionistas e uma compreensão de interdependência com a natureza, embora sem um grau de aprofundamento significativo. Também mostraram uma valorização do meio ambiente e compreensões das contradições existentes na atualidade, fazendo relações com diferentes áreas do conhecimento. Tais características dos resultados mostram o potencial dos(as) professores(as) em construir novas possibilidades de relacionamento com a natureza.

PALAVRAS-CHAVE: Educação Ambiental. Formação de professores. Preferências ambientais.

RESUMEN: Se presenta un análisis de las concepciones de Educación Ambiental de los maestros de las escuelas municipales de Matinhos, Paraná, Brasil. La investigación fue enfoques cuantitativos y cualitativos. En el enfoque cuantitativo se elaboró un cuestionario con preguntas basadas en temas generales de la Educación Ambiental considerando la relación entre el ser humano y el medio ambiente, con la participación de 51 maestros. El análisis se realizó a través de la metodología estadística. En el enfoque cualitativo, se realizaron entrevistas con 13 maestros y ellas fueron transcritas y analizadas utilizando la

\footnotetext{
${ }^{1}$ Secretaria Municipal de Educação (SME), Matinhos - PR - Brasil. Professora na Escola Municipal Wallace Tadeu de Mello e Silva. Mestrado em Rede para o Ensino das Ciências Ambientais (UFPR). ORCID: https://orcid.org/0000-0002-4150-5537. E-mail: ruthcatao@gmail.com

${ }^{2}$ Universidade Federal do Paraná (UFPR), Matinhos - PR - Brasil. Professor do Ensino Básico e Tecnológico. Doutorado em Ciências (USP). Bolsista de Produtividade em Pesquisa do CNPq - Nível 2. ORCID: https://orcid.org/0000-0002-7339-9476. E-mail: joucoski@ufpr.br

${ }^{3}$ Universidade Federal do Paraná (UFPR), Matinhos - PR - Brasil. Professor no Programa de Pós-Graduação em Rede para o Ensino das Ciências Ambientais. Doutorado em Educação Ambiental (FURG). ORCID: https://orcid.org/0000-0003-2612-6624. E-mail: christiano@ufpr.br
} 
técnica de Análisis Textual Discursivo. Los resultados muestran aspectos conservacionistas y una comprensión de la interdependencia con la naturaleza, aunque sin un grado significativo de profundización. Los resultados también mostraron una apreciación del medio ambiente y la comprensión de las contradicciones actuales que conectan diferentes áreas del conocimiento. Tales características de los resultados muestran potencialidades de los maestros construir nuevas posibilidades para relacionarse con la naturaleza.

PALABRAS CLAVE: Educación Ambiental. Formación del profesorado. Preferencias ambientales.

ABSTRACT: This paper presents an analysis of the conceptions about Environmental Education of the teachers of municipal basic education schools, in Matinhos, Paraná, Brazil. The research was quantitative and qualitative approaches. In the quantitative approach a questionnaire was elaborated with questions based on overall themes of the Environmental Education considering the relationship between the human being and the environment, with the participation of 51 teachers. The analysis was carried out using a statistical survey. In the qualitative approach a total of 13 teachers were interviewed and after the interviews were transcribed and analyzed by the Discursive Textual Analysis. The results show preservationists/conservationists aspects and a understanding of the interdependence with the nature, without a degree of significant deepening. Results also showed an enhancement the environment and understandings of the current contradictions connecting different areas of the knowledge. Such characteristics of results shows potential to construct with these teachers' new possibilities in the relations between the human being and nature.

KEYWORDS: Environmental Education. Teachers education. Environmental preferences.

\section{Introdução}

Este trabalho se trata de uma pesquisa descritiva exploratória que tem como principal questão: Qual ou Quais concepções de Educação Ambiental (EA) estão presentes nos docentes das escolas de Matinhos? Como referência para a identificação das concepções da EA foram utilizadas principalmente as concepções de EA historicamente presentes no Brasil (RUSCHEINSKI，2014; LOUREIRO; LAYRARGUES，2013; GUIMARÃES，2013; LOUREIRO, 2012; SAUVÉ, 2005). As análises também seguiram essas concepções e as de alguns autores internacionais.

A EA vem ao longo da história sendo compreendida como parte fundamental para o desenvolvimento humano. Os vários conceitos com os quais identificamos os ambientes dão origem a processos de promoção da EA a medida em que se vê a necessidade de que o ser humano a veja como parte de si, e não somente, como descreve Loureiro (2012), o ser humano externo ao ambiente. 
Em relação ao currículo, normativamente se caracteriza pelo processo vivido na escola que faz parte do trabalho a ser desenvolvido na mesma, é um conjunto contínuo de situações relativas à aprendizagem escolar. Para Lopes e Macedo (2013), quando se trata de currículo consideram-se processos culturais e ideológicos com suas relações de poder. Assim, o currículo não é apenas uma lista de conteúdos prontos a serem transmitidos aos alunos e não se esgota na aplicação do conhecimento às experiências do dia a dia, o que torna interessante que o professor conheça o entorno da escola em que leciona, a comunidade na qual sua escola se encontra inserida e vice-versa, pois é somente nesta completude de conhecimentos que há promoção do saber.

O município de Matinhos está localizado no litoral do estado do Paraná e se encontra em uma região costeira que possui um mosaico de unidades ambientais, com uma presença significativa de Floresta Tropical Atlântica relativamente bem preservada e grandes áreas com coberturas de manguezais (NETO, 2018). Ele conta com uma população projetada de 34.207 habitantes (IBGE, 2018), e apesar de existir pesquisa sobre o currículo das escolas municipais em Matinhos (KEMPA, 2011), ela não focava nas concepções de EA dos(as) professores(as) das escolas municipais do Ensino Fundamental I (EFI). Além disso, houve facilidade de acesso às informações junto à Secretaria Municipal de Educação. O município possui uma área que compreende uma grande diversidade de possibilidades com relação ao desenvolvimento de uma EA mais abrangente. Os estudos sobre as concepções de EA nas escolas de Matinhos são importantes pois o município está numa das maiores regiões de floresta de Mata Atlântica contínua do Brasil. Segundo Diegues (2015, p. 01):

[...] esta é minha primeira visita a Matinhos, mas, de alguma forma, eu a conhecia através de seus pescadores. Pude constatar que Matinhos continua com sua tradição pesqueira, que, como ocorre com outras cidades não tem consciência do patrimônio cultural de que dispõe e que a torna distinta de tantas outras onde esse modo de vida está desaparecendo.

Esse relato contribuiu na visão de que os cidadãos matinhenses "não têm consciência do patrimônio de que dispõe esta cidade". Essa fala nos possibilitou relacionar através da EA como os(as) professores(as) podem vir a compreender as questões ambientais na região e verificar suas concepções de EA que estão presentes no âmbito das escolas municipais.

\section{Procedimentos Metodológicos}

A pesquisa se desenvolveu com professores(as) de todas as escolas de EFI do município, atuantes em sala de aula, que se dispuseram a participar. $\mathrm{O}$ município possui um 
Plano de Trabalho Docente (PTD) que serve como referência à EA em sala de aula através das competências cabíveis à área de ensino de ciências. Também uma Cartilha de Planejamento da secretaria de educação do município em que os conteúdos do eixo relacionados ao desenvolvimento tecnológico e Educação Ambiental deverão perpassar os demais eixos, e também como as questões ambientais da comunidade deverão ser exploradas e abordadas de forma global em todos os aspectos discutidos, ou seja, nesse nível de ensino está mais nítido o desenvolvimento junto aos alunos dos conceitos de Ensino de Ciências e de Ambiente.

No primeiro semestre de 2017 fez-se contato com a Secretaria Municipal de Educação de Cultura, a fim de buscar informações sobre os(as) professores(as) do município. A secretária de Educação orientou o acesso ao Portal da Transparência Municipal disponibilizado no site da Prefeitura do Município, onde foi possível encontrar os dados dos docentes, cargos que ocupam, salários e tipos de vínculos.

Nesse mesmo processo foram acessados os Projetos Políticos Pedagógicos (PPP's) das escolas, buscando-se tópicos que descreviam o que está previsto para EA no âmbito escolar e a caracterização da comunidade escolar que a mesma atende, a fim de com estas informações fosse possível uma caracterização prévia do público pesquisado e também que fornecessem subsídios para a construção dos instrumentos de pesquisa.

$\mathrm{Na}$ primeira parte da pesquisa, que foi de cunho quantitativo, foi elaborado um questionário, cujas questões se basearam em temas gerais da EA, considerando as relações entre o ser humano e o meio ambiente, disponibilizados impressos ou on-line, atendendo a necessidade de cada professor, a fim de incluir o maior número possível de respondentes na pesquisa. As questões foram divididas em conjuntos de identificação: conjunto de preferências relacionadas à EA no qual os mesmos puderam escolher mais de uma alternativa; conjunto de preferências para moradia, lazer e alimentação; e conjunto de descrições de correntes e concepções de EA, sem a identificação de qual estava sendo descrita. Foram contatados os 169 professores(as) das escolas municipais e solicitada sua participação; desses, 51 responderam (30\% do total). Os questionários foram respondidos pelos professores(as) entre março e maio de 2018.

No sentido de aprofundar o conhecimento a respeito das concepções de EA dos(as) professores(as), a segunda parte da pesquisa foi de cunho qualitativo, em que foram realizadas entrevistas semiestruturadas. Houve a participação de 13 professores(as), um(a) de cada escola, sendo que em uma das escolas não houve professor(a) que aceitasse o convite ou se voluntariasse a participar. Nomes fictícios foram utilizados para os(as) professores(as) 
entrevistados, visando preservar suas identidades. Para as análises das entrevistas usou-se a técnica da Análise Textual Discursiva que "se caracteriza por uma leitura cuidadosa e aprofundada dos dados em um movimento de separação das unidades significativas" (SANTOS; DALTO, 2012, p. 6). Esta técnica de pesquisa é descrita como:

[...] um processo que se inicia com uma unitarização em que os textos são separados em unidades de significado. Estas unidades por si mesmas podem gerar outros conjuntos de unidades oriundas da interlocução empírica, da interlocução teórica e das interpretações feitas pelo pesquisador. Neste movimento de interpretação do significado atribuído pelo autor exercita-se a apropriação das palavras de outras vozes para compreender melhor o texto. (MORAES; GALIAZZI, 2006, p. 118).

Neste sentido, coloca-se na posição de detalhar e interpretar o outro: considerou-se inicialmente a descrição do questionário dos sujeitos respondentes para então verificarmos o perfil inicial dos(as) professores(as) para, em seguida, construírem-se as questões das entrevistas. As entrevistas foram realizadas entre junho e julho de 2018.

\section{Resultados e discussão}

Analisando as respostas dos questionários, no conjunto de preferências relacionadas à EA, verificou-se que os(as) professores(as) consideram importantes com maior destaque para as opções "Cuidar do planeta e de todos os seres vivos, afinal somos parte de um todo" (39 \%), “A separação do lixo, mas verificando se o órgão competente dá a esse lixo o destino correto" (18\%) e "O não desmatamento e o plantio de árvores para limpar o ar do planeta" (14\%). Lembrando que cada professor poderia escolher mais de uma opção. Embora o conjunto das sete opções possíveis para os(as) professores(as) responderem estivessem relacionadas a aspectos mais conservacionistas da EA, a que prevaleceu possui um grau de entendimento mais próximo do ser humano com suas relações socioambientais. Isto mostra um entendimento da relação entre o ser humano e a natureza como um processo que possibilita compreender novos paradigmas destas relações (NOGUEIRA, 2019).

Em relação ao conjunto de preferências para moradia, lazer e alimentação, observou-se (Figura 1) mais destacadamente que as preferências entre meios rurais (sítio/chácaras, 78\%), vegetação $(80 \%)$ e mar/praia $(84 \%)$ junto com comidas caseiras $(86 \%)$, rios $(78 \%)$, comidas tradicionais $(84 \%)$ tendem a ser maiores em relação aos ambientes com características urbanas, como prédios (12\%), shopping (28\%) e fastfood (22\%). É interessante observar que a maioria prefere ruas pavimentadas $(61 \%)$. 
Figura 1 - Gráfico de preferências dos docentes em relação a alguns ambientes, sendo estes interioranos, urbanos e naturais

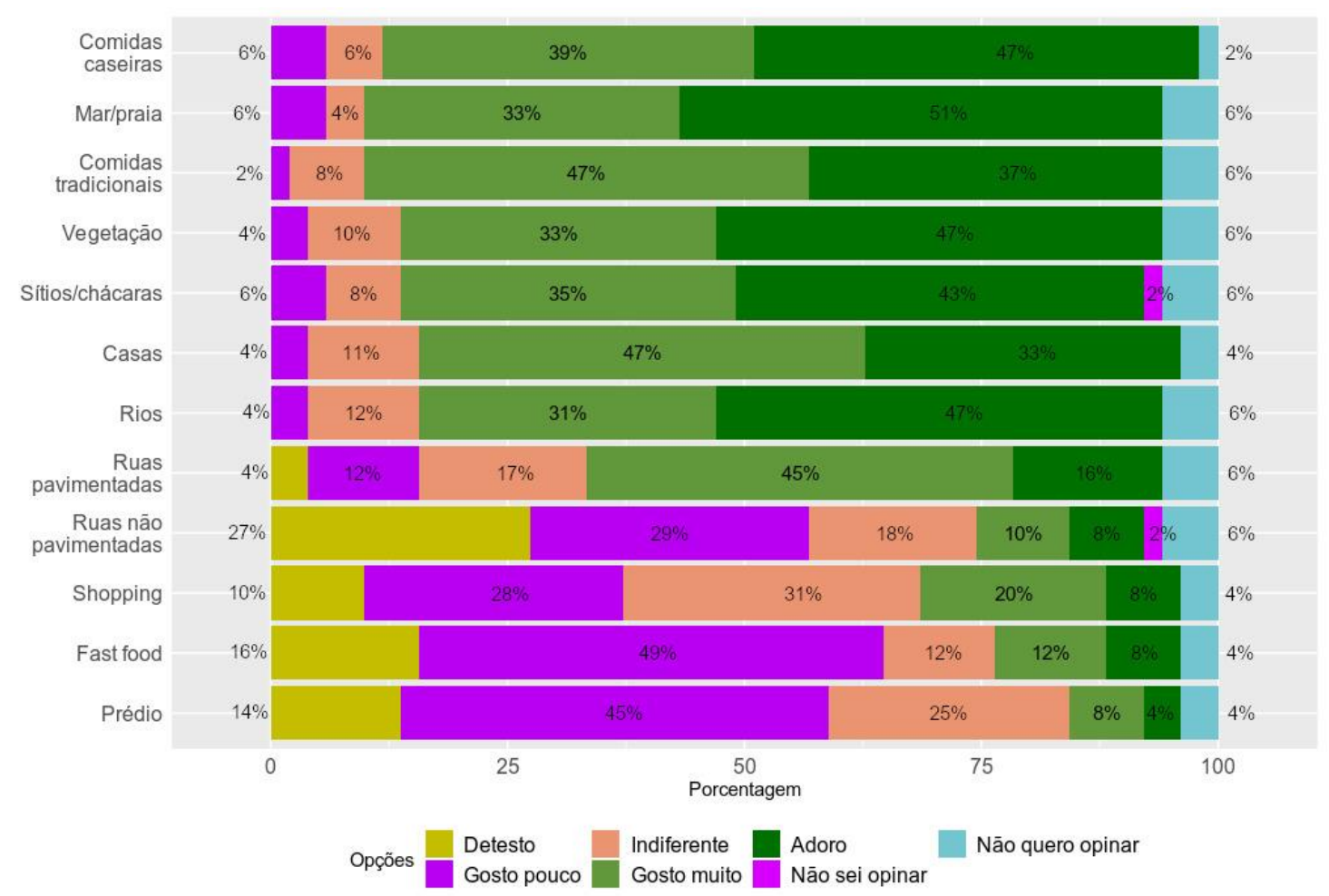

Fonte: Acervo dos autores

Verifica-se à esquerda da Figura 1 que as preferências estão apresentadas de cima para baixo de acordo com aquelas mais voltadas a uma maior aproximação a meios e culturas que possuem uma maior valorização do meio ambiente, até aquelas relacionadas a processos industrializados e urbanizados das relações entre o ser humano e a natureza. Assim, observando que as opções respondidas como "adoro" e "gosto muito", com cores mais esverdeadas, apresentam um certo destaque, já que prevalecem de forma significativa à direita do gráfico, que representa um maior percentual, e a na parte superior, que está relacionada a uma maior valorização do meio ambiente. Trata-se de uma visão que, segundo Boff (2017), apresenta um potencial para que seja possível assumir novos hábitos e projetar um desenvolvimento que seja capaz de cultivar o cuidado com os equilíbrios ecológicos, de acordo com os limites existentes na natureza. Esta visão possibilitaria compreender as contradições existentes nas relações entre o ser humano e a natureza e também a possibilidade de as superar (TREIN, 2018). 
Como descrito nos procedimentos metodológicos, os(as) professores(as) analisaram sentenças associadas àquelas correntes e concepções de EA, sem um título que as identificassem, e escolheram as que apresentavam ideias e concepções que estivessem de acordo. Estas correntes e concepções foram definidas a partir das concepções dos principais autores existentes na EA brasileira, sem seguir com uma rigidez para que se encaixassem perfeitamente com estas definições. Mesmo porque algumas correntes e concepções definidas através de nomenclaturas de seus autores podem ou não comungar com bases epistemológicas de outros. Cada professor podia escolher até três opções, embora um deles tenha escolhido quatro.

Para a EA Crítica, de acordo com Loureiro e Layrargues (2013), Guimarães (2013), Loureiro (2012) e Sauvé (2005) a sentença foi “a Educação Ambiental que expõe as condições que estão no centro do modo de produção capitalista e que deve incentivar a participação social na forma de uma ação política. Essa Educação Ambiental deve ser aberta ao diálogo e ao embate, visando a explicitação das contradições reais relacionadas a projetos societários que estão permanentemente em disputa". Para a EA Conservadora, conforme Guimarães (2013), Loureiro (2012) e Sauvé (2005), usou-se “a Educação Ambiental que afirma que a sociedade foca numa compreensão natural e conservadora da crise ambiental onde se aborda um entendimento reducionista, biologizante e fragmentado sobre a questão ambiental e compreende a natureza como algo exterior que rodeia a vida humana".

Para a EA Emancipatória, de acordo com Loureiro (2012), Canabarro, Oliveira e Silva (2009) e Loureiro (2006), a frase foi “a Educação Ambiental voltada para um projeto alternativo global onde a preocupação não está apenas na preservação da natureza ou no impacto das sociedades humanas sobre os ambientes, mais num novo modelo de civilização sustentável do ponto de vista ecológico, que implica uma mudança nas estruturas econômicas, sociais e culturais”. Para a EA Transformadora, conforme Rocha, Rocha e Hammes (2016), Loureiro (2012) e Loureiro (2004), a frase foi, “a Educação Ambiental que afirma a educação enquanto prática social que contribui no processo de construção de uma sociedade pautada por novos patamares civilizacionais e societários distintos dos atuais, em que a sustentabilidade da vida e a ética ecológica sejam os temas centrais".

Para a EA relacionada à Gestão Ambiental, conforme Dias (2017), MMA(1996) e Sauvé (2005) a frase foi, “a Educação Ambiental que tem por objetivo proporcionar condições para o desenvolvimento de capacidades (dos conhecimentos, das habilidades e das atitudes) visando a intervenção individual e coletiva, de modo qualificado, tanto na gestão do uso dos recursos ambientais quanto na concepção e aplicação de decisões que afetam a 
qualidade do meio ambiente, seja ele natural ou artificial". Para a EA da Alfabetização Ecológica, de acordo com Capra et al. (2018) e Munhoz (2004), a sentença foi, "a Educação Ambiental que consiste no conhecimento, internalização e implementação de princípios ecológicos nas comunidades humanas: interdependência, cooperação e parceria, coevolução, flexibilidade, diversidade, equilíbrio dinâmico, reciclagem e ciclos ecológicos, fluxo de energia e redes".

Para a EA Ecopedagógica, de acordo com Gadotti (2017), Ruscheinski (2014) e Guti rrez e Prado (2013), a sentença foi "a Educação Ambiental que procura enfatizar e associar as noções de mudança social e cultural, de emancipação/libertação individual e social e de integração no sentido de maior complexidade". A Figura 2 mostra as concepções mais escolhidas relacionadas às sentenças descritas acima:

Figura 2 - Gráfico de Correntes e concepções de EA mais escolhidas

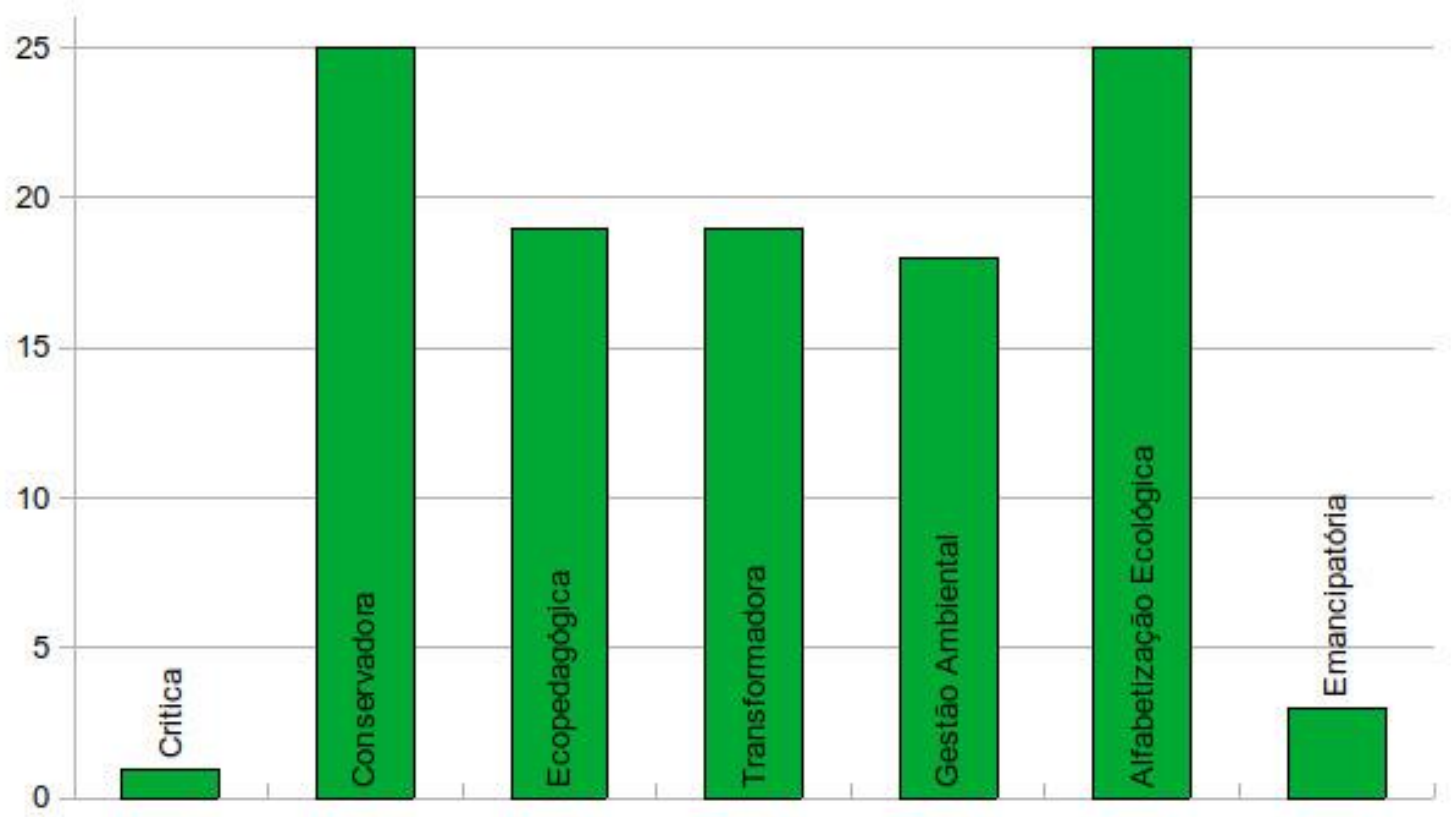

Fonte: Acervo dos autores

Assim, conforme A Figura 2, houve 110 escolhas totais de professores(as). Também importa salientar que alguns(mas) professores(as) escolheram três, outros duas e outros uma opção, além daquele(a) professor(a) que escolheu quatro. Neste gráfico observa-se o destaque para as EA "Alfabetização Ecológica" e "Conservadora”. Estas duas correntes e concepções, juntamente com a EA da Gestão Ambiental, que também aparece de forma significativa na Figura 1, possuem características de enfoques mais relacionados a concepções preservacionistas/conservacionistas da EA. São perspectivas que não identificam o ser humano como um ser ao mesmo tempo biológico e cultural, com suas relações com o meio 
ambiente e seus semelhantes de forma mais integrada e equilibrada. Trata-se, conforme Layrargues (2012), de uma perspectiva que é estrita ou majoritariamente ecológica relacionada aos problemas ambientais através do paradigma antropocêntrico e cartesiano ao egocêntrico e ecossistêmico. Ainda conforme esse autor, o ser humano é destituído de qualquer recorte social, considerando de forma exclusiva a sua condição como espécie biológica. Nesta perspectiva, a transformação na sociedade ocorre como consequência de uma transformação individual com uma educação teórica e basicamente transmissora de informações, além de comportamentalista (GUIMARÃES, 2013).

Entretanto, de forma significativa, o resultado mostra também as correntes e concepções de EA Ecopedagógica e Transformadora. Assim, embora a análise anterior nos mostre perspectivas relacionadas a compreensões preservacionistas/conservacionistas, os(as) professores(as) também se identificaram com perspectivas de uma EA voltada a um pensamento crítico nas relações entre o ser humano e o meio ambiente. São perspectivas que, segundo Loureiro (2012), a EA envolve uma práxis social que possibilitaria a construção de novas relações de produção, com um outro modelo econômico, social, cultural e histórico, onde os seres humanos possuiriam uma centralidade na atuação política. Nesta perspectiva, a aceitação dos problemas ambientais e a percepção destes existirem não se trata apenas de uma abordagem cognitiva, mas, sim, com relação ao meio social e cultural em que prevalece interesses econômicos, políticos e ideológicos. Tal base teórica e metodológica permite mostrar aspectos ideológicos, políticos e ecológicos relacionados aos problemas ambientais (PENELUC; PINHEIRO; MORADILLO, 2018). As correntes e concepções de EA Crítica e Emancipatória não aparecem de forma significativa na Figura 2, embora possuam uma base epistemológica mais próxima das correntes e concepções de EA Ecopedagógica e Transformadora.

Desta forma, podemos verificar uma contraditoriedade no entendimento dos(as) professores(as) a respeito da EA nas entrevistas. Nas escolhas de concepções e correntes de EA verificou-se que, assim como foi uma pretensão desta pesquisa, não houve uma rigidez para que os(as) professores(as) se encaixassem em determinadas concepções e correntes que comungam de uma fundamentação epistemológica. Como sujeitos históricos em seus diversos processos de interações sociais, culturais e ambientais fazem com que suas construções teóricas estabeleçam conexões com as mais diversas formas de interpretar as relações sociais e ambientais. Assim, o consenso, os conflitos e os interesses são inerentes às estruturas e formas de organização da sociedade, e desempenham um papel central no modo como os 
sujeitos pensam sobre as relações entre si e suas relações com a natureza (STAHELIN; ACCIOLY; SÁNCHEZ, 2015).

Em relação às entrevistas, como forma de se compreender com mais profundidade as concepções de EA dos(as) professores(as), verificamos falas que mostram conhecimentos relacionados às contradições existentes na sociedade como geração de empregos e o desenvolvimento econômico e seus impactos ambientais gerados. A fala do professor Ricardo mostra isso:

A questão de desmatamento uma questão que impacta muito $n$ ! No meio ambiente! Falando em geração de empregos tem a estrada do porto que vai sair ali n! Vai ser bom pro nosso município $n$ ! Vai ter que ocorrer o sacrificio de algum lugar. (Ricardo)

Este entendimento é condição para o desenvolvimento de concepções de uma EA com uma abordagem mais crítica. Neste caso há um entendimento das questões ambientais que não envolvem somente pensar conservação e preservação, mas também questões que envolvem interesses econômicos e impactos sociais.

Este mesmo professor coloca esta questão ao refletir sobre alguns problemas ambientais, destacando durante a entrevista que as queimadas são um grande problema ambiental e ao se justificar diz:

Queimadas porque na verdade assim a partir do momento que acaba queimando, árvores, plantas a gente sabe que ali tem muito seres viventes naquela região $n$, das queimadas. Queimou aquela coisa $n$ ! Acaba com as árvores que o que gera nosso oxigênio, $n$ ! A vida naquele local também acaba se destruindo por que dependendo da queimada muito extensa ela acaba com aquela região. (Ricardo)

São compreensões que mostram que além do prejuízo ao ser humano, as queimadas são maléficas a outros seres vivos, incluindo-se como parte do ambiente e como um ser vivo prejudicado. Desta maneira pode-se entender que o professor possui uma noção conceitual de ambiente mais atual, na qual visualiza-se as necessidades de uma EA mais profunda, que não valorize apenas cuidar para sobreviver e utilizar, mas para além disso, exigindo assim uma mudança de postura, de cultura. É uma abordagem dos problemas ambientais que se relacionam a uma EA que, segundo Costa e Loureiro (2017), possui um conhecimento resultado de uma interação humana planetária e ecológica, ou seja, um relacionamento que envolve um conhecimento interdisciplinar. A fala da professora Rana refere-se a respeito dos problemas ambientais: 
A questão do aumento da população e da água são dois assim muito importante, porque o pessoal assim, ainda não se conscientizou de que a água vai faltar, que hoje nós já pagamos no copinho da água três (reais) e pouco. Porque eles acham assim: Ah vem da torneira a gente paga lá 50,00 - 60,00 reais e água vem $n$, mas ela vai acabar. A questão da população um caso bem sério, por que assim nós atendemos aqui mães que cada um de um pai, acho que falta não deixar lá uma cartela de comprimido, uma camisinha, orientar $n$, mobilizar $n$, aquela coisa do planejamento familiar. (Rana)

Nesta fala verifica-se a preocupação com os problemas ambientais relacionados ao excesso populacional, tanto que em sua fala aborda sobre planejamento familiar e sobre o uso da água sem consciência. Os relatos destes dois professores mostram ideias que podemos aproximar às de Peneluc, Pinheiro e Moradillo (2018), pois possibilita uma EA com uma base teórica e metodológica de grande valor, já que permite desvelar aspectos ideológicos, político e ecológicos da crise socioambiental. Tais aspectos, envolvendo também a territorialidade e o sentimento de pertencimento, podem ser observados no relato do professor a seguir, sobre os ambientes que podemos encontrar na cidade:

Oh! Esse braço do rio que tem aqui ninguém botaf , mas o rio Guaragua u, ele começa em Matinhos, ele começa aqui no Sert ozinho (Bairro de Matinhos, grifo nosso), dai ele faz assim, são três braços... Eh! Aqueles bueiros da beira da estrada ele vai e forma um rio maiorzinho aqui, dai aqui tem um morro o único morro que tem do lado de cá, o morro do Mamote, esse rio passa aqui, o rio do Mamote e dão os três bueiros de lá que at chegar na Copiosa Redenção são mais três bueiros. Daí, aqui forma o rio do Porto da Goiabeira que eles falam, dai ali eles tiram caixeta ali, conheci desde de criança aquilo ali... Então aqui forma um rio grande [...] mas não calúnia, eu tô falando a verdade por que quando eu trabalhava no projeto do PET a gente plantou muda inclusive eu peguei ali do parque muda de Aroeira, de Palmito... por que a Aroeira assim, além dela segurar a erosão ela traz os pássaros de volta por que uma fruta que todos os passarinhos comem, Sanhaço, Sa ra, Sabiá, Tucano, Tiriba, tudo come. Então, a nossa ideia era essa aqui. Então, a gente plantou cem mudas ali. Depois de grande veio a máquina limpar o rio e derrubou tudo, só que nós não tava mais lá por que caiu o barracão lá, sabe. Daí nós viemos aqui pro Galo Bom. Então perdemos. (Roger)

Verifica-se nesse relato a relação cultural e íntima que o professor tem com a região. Trata-se de uma fala que traz a cultura, costumes e identidade. De acordo com Cardoso et. al. (2017), na fala deste professor verifica-se um sentimento de pertencimento, pois implica olhar e reconhecer-se no local onde vive. Outra professora, ao recordar suas lembranças, traz a ideia de uma prática econômica antiga da região, que foi a produção de farinha de mandioca:

Aqui tem muitos pescadores. Os pescadores, eles antigamente $n$ se sustentavam, trabalhavam ali e tiravam dali o seu sustento, ali eles comiam 
o peixe, também vendiam e compravam as outras coisas. Acho que isso n! uma sociedade que se sustenta por si só $n$ ! Igual aqui no Rio da Onça. Meu av fazia farinha já era uma economia familiar sustentável, agora acabou $n$. Porque ele morreu e os filhos não continuaram. (Renata)

Este processo econômico antigo retratado em sua fala mostra que há uma cultura local que, em dada época, foi de grande valor para região e que já não se faz mais. Produção de farinha como fonte de renda deixa de ter um grande valor, já que está sendo sobreposta pelo turismo sazonal. Mesmo com estas mudanças se verifica na fala da professora Renata uma identidade e um pertencimento ao território onde vive. Este pertencimento possibilita pensar em si mesmo como integrante de uma sociedade que atribui símbolos e valores éticos e morais, o que destaca características culturais (CARDOSO et al., 2017).

Após a análise das falas de alguns professores sobre as questões ambientais e suas relações com processos culturais, econômicos, sociais e de pertencimento que possibilitam conhecer alguns fundamentos de suas concepções de EA, analisamos também as falas especificamente a respeito da EA. A fala a seguir, da professora Rana, mostra o seu pensamento a respeito da importância da EA para se chegar à sustentabilidade:

A sustentabilidade acho assim que ela depende da Educação Ambiental na prática. Seja feita na prática, se você não entendeu que a Educação Ambiental, você nunca vai chegar a sustentabilidade, porque você, os insetos não entendem que fazendo um shopping você est desestabilizando os animais, os ambientes. Você tá desrespeitando a cadeia alimentar. Ah feio, mato feio, então eu vou fazer uma coisa bem bonita lá. Mas você não entende. Então eu acho que pra haver sustentabilidade tem que ter um EA, mais assim muito acirrada, por que as pessoas não vão entender. $\mathrm{Na}$ verdade, eles não sabem o que . (Rana)

Trata-se de um entendimento a respeito da importância da EA para a sustentabilidade em que se apresenta elementos relacionados à interferência da atividade humana no meio ambiente. Nesta fala verifica-se a possibilidade de uma construção teórica de aspectos que envolvem uma abordagem mais crítica da EA. Na fala a seguir, a abordagem é parecida em relação à falta de cuidado, neste caso falando da relação com a natureza e a vida:

A Educação Ambiental necessária $n$, porque diante de tanta coisa que est acontecendo, de tanta inconsciência, porque as pessoas não cuidam mais de nada sendo natureza ou não. Não se cuida mais de nada de ninguém. Hoje não se tem mais valor, a própria vida não tem valor. Imagina uma árvore. Esta coisa de dar valor as vezes as pessoas não lembram. (Regina) 
A professora faz um discurso reflexivo sobre a ausência de uma coletividade e a importância da valorização da vida na sociedade. Para a professora Clara, a abordagem ao ser questionada sobre a importância da EA é mais direta:

A questão de sobrevivência mesmo $n$, se tiver tudo poluido você vai sobreviver como se não tiver ar puro. É questão da sobrevivência mesmo, $n$ ! (Clara)

As falas das professoras mostram uma conexão de conhecimentos que não é específica de uma área. Ao abordar sobre as problemáticas da sociedade aliadas a questões ambientais em conjunto com o abordado anteriormente, ou seja, suas relações com processos culturais, econômicos, sociais e de pertencimento, possibilitam verificar indícios de concepções de EA que se aproximam das correntes e concepções de EA Ecopedagógica e Transformadora. Embora estas duas correntes e concepções não tenham sido as de maior destaque na pesquisa quantitativa, elas apareceram de forma significativa, conforme a Figura 2. Isso mostra que as compreensões dos(as) professores(as), embora não tenham uma base teórica bem fundamentada, possuem aproximações com a construção teórica de uma EA relacionada com as correntes e concepções como a Ecopedagógica, a Emancipatória e a Crítica. Envolvem conhecimentos que possibilitam compreender as contradições de uma sociedade pautada em relações de produção que expressam o modelo econômico, social, cultural e político da atualidade, bem como superá-las (PENELUC; PINHEIRO; MORADILLO, 2018; TREIN, 2018; GUIMARÃES; 2013; LOUREIRO, 2012). Tais aproximações possibilitam o desenvolvimento de concepções com uma fundamentação mais crítica de correntes e concepções de EA.

\section{Considerações finais}

A partir das correntes e concepções de EA descritas nesta pesquisa observamos que os(as) professores(as) da rede municipal de Matinhos possuem características significativas a respeito de como pensam a EA. Como verificamos, ao se analisar o conjunto de preferências relacionadas à EA, os(as) professores(as) apresentaram destacadamente o cuidar do planeta $\mathrm{e}$ de todos os seres vivos, o não desmatamento e o plantio de árvores para limpar o ar do planeta. Tais aspectos mostram uma compreensão de interdependência com a natureza, embora sem um grau de aprofundamento significativo. Mesmo assim, podemos considerar como próximo de um entendimento do ser humano com suas relações socioambientais. Este entendimento também foi verificado no conjunto de preferências para moradia, lazer e 
alimentação, em que os(as) professores(as) mostraram uma maior valorização do meio ambiente. Isto possibilita compreensões das contradições existentes na atualidade e de novas formas de nos relacionarmos e reconhecermos os limites da natureza (NOGUEIRA, 2019; BOFF, 2017; TREIN, 2018).

Em relação ao conjunto de descrições de correntes e concepções de EA, os(as) professores(as) mostraram aspectos contraditórios no entendimento a respeito da EA. Da mesma forma que demonstraram afinidades com aspectos da Alfabetização Ecológica da EA Conservadora e da EA da Gestão Ambiental, com características preservacionistas/conservacionistas da EA, também demonstraram afinidades com a aspectos da EA Ecopedagógica e da EA Transformadora. Tais informações corroboram a possibilidade de compreensões das contradições existentes atualmente para se construir novas formas de relações com a natureza.

As informações apresentadas nas entrevistas possibilitam verificar de forma mais clara as compreensões de interdependência com a natureza e das contradições existentes nas relações socioambientais na atualidade. As relações com processos culturais, econômicos, sociais e de pertencimento possibilitam verificar indícios relacionados a correntes concepções de EA que se aproximam da EA Ecopedagógica e da EA Transformadora, bem como um conhecimento relacionado a diferentes áreas. Ardoin, Clark e Kelsey (2013), em pesquisas sobre as futuras tendências na pesquisa em EA em nove países, incluindo o Brasil, verificaram a necessidade de a EA envolver o conhecimento de diversas áreas considerando o contexto global, com os seus aspectos econômicos, sociais, étnicos, culturais etc. Tais resultados indicam também que o contexto do litoral paranaense pode possuir um papel relevante nas compreensões sobre a EA para os(as) professores(as) da rede municipal de Matinhos.

\section{REFERÊNCIAS}

ARDOIN, N. M.; CLARK, C.; KELSEY, E. An exploration of future trends in environmental education research. Environmental Education Research, v. 19, n. 4. 2013.

BOFF, L. Sustentabilidade: o que é e o que não é. Petrópolis, Editora Vozes, 2017.

BRASIL. INSTITUTO BRASILEIRO DE GEOGRAFIA E ESTATÍSTICA - IBGE. Tabelas dos Municípios - Estimativas 2018. Disponível em:

https://agenciadenoticias.ibge.gov.br/agencia-detalhe-de-

midia.html? view=mediaibge\&catid=2103\&id=2279. Acesso em: 03 ago. 2020 . 
CANABARRO, C. L.; OLIVEIRA, C. T.; SILVA, M. F. S. Aproximações entre Paulo Freire e Educação Ambiental Emancipatória: uma análise partindo da ética, da estética, da política e da epistemologia. Revista Eletrônica do Mestrado em Educação Ambiental, v. 23, p. 385 393, jul./dez. 2009. DOI: https://doi.org/10.14295/remea.v23i0.4567

CAPRA, F. Alfabetiza o ecol gica. São Paulo: Cultrix; 2018.

CARDOSO, D.; CURA, S.; VIANA, W.; QUEIROZ, L.; COSTA, M. Espacialidades e ressonâncias do patrimônio cultural: reflexões sobre identidade e pertencimento. GOT Revista de Geografia e Ordenamento do Território, Portugal, n. 11, n. 83-98, 2017. DOI: http://dx.doi.org/10.17127/got/2017.11.004

COSTA, C. S.; LOUREIRO, C. F. B. A interdisciplinaridade em Paulo Freire: aproximações político-pedagógicas para a educação ambiental critica. Revista Kat lysis, Florianópolis, v. 20, n. 1, p. 111-121, 2017. DOI: http://dx.doi.org/10.1590/1414-49802017.00100013

DIAS, G. F. Educação e gestão ambiental. São Paulo, Gaia, 2017.

DIEGUES, A. C. Territórios e comunidades tradicionais. In: SIMPÓSIO BRASILEIRO DE DESENVOLVIMENTO TERRITORIAL SUSTENTÁVEL, 1., 2015, Matinhos. Anais [...]. Matinho, PR: Universidade Federal do Paraná, 2015.

GADOTTI, M. Pedagogia da terra. São Paulo: Peirópolis, 2017.

GUIMARÃES, M. Por uma Educação Ambiental Crítica. Revista Margens Interdisciplinar, v. 7, n. 9, 2013.

GUTI RREZ, F.; PRADO, C. Ecopedagogia e cidadania planetária. São Paulo: Cortez, 2013.

KEMPA, S. R. Políticas de currículo em Matinhos- PR: a voz dos professores. 2011. $190 \mathrm{f}$. Tese (Doutorado em Educação: Currículo) - Pontifícia Universidade Católica de São Paulo, São Paulo, 2011.

LAYRAGUES, P. P. Para onde vai a educação ambiental: o cenário político-ideológico da educação ambiental brasileira e os desafios de uma agenda política crítica contra-hegemônica. Revista contemporânea de Educação, v. 7, n. 14, 2012.

LOPES, A. C.; MACEDO, E. Teorias de currículo. São Paulo: Cortez Editora, 2013.

LOUREIRO, C. F. B. Complexidade e dialética: contribuições práxis política e emancipatória em Educação Ambiental. Educação e Sociedade, Campinas, v. 27, n. 94, p. 131-152, 2006. DOI: https://doi.org/10.1590/S0101-73302005000400020

LOUREIRO, C. F. B. Educação ambiental transformadora. In: LAYRARGUES, P. P. (Coord.) Identidades da Educação Ambiental Brasileira. Brasília, DF: Ministério do Meio Ambiente, 2004. p. 65-84.

LOUREIRO, C. F. B. Trajetória e fundamentos da educação ambiental. São Paulo: Cortez Editora, 2012. 
LOUREIRO, C. F. B.; LAYRARGUES, P. P. Ecologia política, justiça e educação ambiental crítica: perspectivas de aliança contra-hegemônica. Trabalho, Educação e Saúde, Rio de Janeiro, v. 11 n. 1, p. 53-71, 2013. DOI: https://doi.org/10.1590/S1981-77462013000100004

MINISTÉRIO DO MEIO AMBIENTE (MMA). Diretrizes para operacionalização do Programa Nacional de Educação. Brasília: Instituto Brasileiro do Meio Ambiente e dos Recursos Naturais Renováveis, 1996.

MORAES, R.; GALIAZZI, M. C. Análise textual discursiva: processo reconstrutivo de múltiplas faces. Ciência \& Educação, Bauru, v. 12, n. 1, p. 117-128, 2006. DOI: https://doi.org/10.1590/S1516-73132006000100009

MUNHOZ, D. Alfabetização Ecológica: de indivíduos às empresas do século XXI. In: LAYRARGUES, P. P. (Coord.). Identidades da Educação Ambiental Brasileira. Brasília, DF: Ministério do Meio Ambiente, 2004. p. 141-155.

NETO, J. C. F. Projeto Litoral Nota CEM: conhecer para melhorar. Disponível em: http://www.litoralnotacem.com.br/textos.htm. Acesso em: 29 maio 2018.

NOGUEIRA, C. Contradictions in the concept of sustainable development: An analysis in social, economic, and political contexts. Environmental Development, v. 30, p. 129-135, 2019.

PENELUC, M. C., PINHEIRO, B. C. S., MORADILLO E. F. Possíveis confluências filosóficas e pedagógicas entre a educação ambiental crítica e a pedagogia histórico-crítica. Ciência \& Educação, Bauru, v. 24, n. 1, p. 157-173, 2018. DOI: https://doi.org/10.1590/1516-731320180010011

ROCHA, N. D.; ROCHA, J. M.; HAMMES, L. J. Educação ambiental transformadora: epistemologia e prática educativa. Revista Eletrônica do Mestrado em Educação Ambiental, v. 33, n. 2, p. 268-285, 2016. DOI: https://doi.org/10.14295/remea.v33i2.5707

RUSCHEINSKY, A. Educação Ambiental e Alguns Aportes Metodológicos da Ecopedagogia Para Inovação de Políticas Públicas Urbanas. In: PEDRINI, A. G.; SAITO, C. H. (Org.).

Paradigmas Metodológicos em Educação Ambiental. Petrópolis: Editora Vozes, 2014. v. 1, p. 47-59.

SANTOS, J. R. V.; DAUTO, J. O. Sobre análise de conteúdo, análise textual discursiva e análise narrativa: investigando produções escritas em Matemática. In: SEMINÁRIO INTERNACIONAL DE PESQUISA EM EDUCAÇÃO MATEMÁTICA, 5., 2012, Petrópolis. Anais [...]. Petrópolis, RJ: V SIPEM, 2012

SAUVÉ, L. Uma cartografia das correntes em educação ambiental. In: SATO, M.; CARVALHO, I. (Org.) Educação Ambiental: pesquisas e desafios. Porto Alegre: Artmed, 2005. p. 17-44.

STAHELIN, N.; ACCIOLY, I.; S NCHEZ, C. The promise and peril of the state in neoliberal times: implications for the critical environmental education movement in Brazil.

Environmental Education Research, v. 21, n. 3, 2015.

RIAEE - Revista Ibero-Americana de Estudos em Educação, Araraquara, v. 16, n. 2, p. 605-621, abr./jun. 2021. e-ISSN: 1982-5587 
TREIN, E. S. An argument for vindicating a Marxist ontology in environmental education research. Environmental Education Research, v. 24, n. 10, p. 1464-1475, 2018.

\section{Como referenciar este artigo}

CHAVES, R. K.; JOUCOSKI, E.; NOGUEIRA, C. As concepções de Educação Ambiental dos(as) professores(as) nas Escolas Municipais de Matinhos, Brasil. Revista IberoAmericana de Estudos em Educação, Araraquara, v. 16, n. 2, p. 605-621, abr./jun. 2021. eISSN: 1982-5587. DOI: https://doi.org/10.21723/riaee.v16i2.12908

Submetido em: 25/09/2019

Revisões requeridas em: 06/05/2020

Aprovado em: 05/10/2020

Publicado em: 01/02/2021 